\title{
Sabahattin Tekingündüz
}

Mersin University, stekingunduz@gmail.com, Mersin-Turkey

\section{A.Öner Kurt}

Mersin University, onerkulyahoo.com, Mersin-Turkey

\section{Hatun Temirci Ayhan}

Ministry of Health, hatun77@windowslive.com, Ankara-Turkey

http://dx.doi.org/10.12739/NWSA.2015.10.4.4B0006

\section{BİR EĞİTIM VE ARAŞTIRMA HASTANESI TEMİZLİK İŞÇİLERİNIN BULAŞICI HASTALIK RİSK VE UYGULAMALARININ DEĞERLENDIRİMESI}

Öz

Bu araştırmanın amacı, temizlik işçilerinin bulaşıcı hastalık risk/uygulamalarının değerlendirilmesi idi. Kesitsel tipteki çalışmanın verileri 1-29 Şubat 2012'de anket aracılığıyla toplanmıştır. Çalışmaya 270 kişi katılmıştır. Ki-Kare Testi kullanılmıştır. Katılımcıların o74.1'inin hijyen/bulaşıcı hastalıklar eğitimi aldığı saptandı. Çalışanların ⒛7'sinin bone-şapka, ○55.6'sının iş gözlüğü hiç kullanmadığı saptandı. Çalışanların o51.9'u iğne batması sonrasında doğru tutumu göstermiyordu. Yanlış tutumun polikliniklerde çalışanlarda daha fazla olduğu ve farkın istatistiksel olarak anlamıı olduğu saptandı. Çalışanların o4.4'ünün ellerini yıkarken "sadece su" kullanarak yanlış davrandıkları, el yıkama davranışının sosyo-demografik özellikler, hijyen/bulaşıcı hastalıklar eğitimiyle ile değişmediği saptandı. Çalışanların 33.7'sinin Hepatit B, ⒍3'ünün tetanoz aşısı yaptırdığı saptandı.

Anahtar Kelimeler: Temizlik Çalışanları, Hastane Enfeksiyonları, El Hijyeni, Bulaşıcı Hastalık, Hastane

\section{THE EVALUATION OF THE RISK AND PRACTICES OF INFECTIOUS DISEASES OF THE CLEANING WORKERS OF A TRAINING AND RESEARCH HOSPITAL}

\section{ABSTRACT}

The aim of this research was evaluation of the risk/applications of infectious diseases of cleaning workers. The data of the study of sectional type was collected by way of questionnaire in 1-29 February 2012. 270 individual participated in the study. Chi-Square Test was used. It was found out that $74.1 \%$ of the participants received hygiene/infectious disease training. It was found out that who never used work bonnet-hat was $20.7 \%$ of the workers, goggles 55.6\%. 51.9\% of the workers weren't conducting correct behaviour following needlestick. Wrong behaviour was more common among the ones working at polyclinics and difference was statistically meaningful. It was found out that $4.4 \%$ of the workers using "only water" while washing their hands behaved wrongly, the behaviour of washing hands didn't change with socio-demographic characteristics, hygiene/infectious disease training. It was found out that $33.7 \%$ of the workers had Hepatitis B, $6.3 \%$ of them tetanus.

Keywords: Cleaning Workers, Hospital İnfections, Hand Hygiene, Infectious Disease, Hospital 
Tekingündüz, S., Kurt, A.Ö. ve Ayhan Temirci, H. Life Sciences (NWSALS), 4B0006, 2015; 10(4): 15-28

\section{GIRIŞ (INTRODUCTION)}

Hastane enfeksiyonları, enfeksiyon dışı bir nedenle hastaneye yattıktan 48-72 saat sonra gelişen, hastanede bulunmayla neden sonuç ilişkisi gösteren, hasta, hastane personeli, hasta refakatçileri ve ziyaretçilerin sağlığını tehdit eden "sağlık hizmeti ilişkili enfeksiyonlar" olup mortalite ve morbidite artışı ile ilişkilidir. Hastanede kalış süresini, işgücü kaybını arttıran, hastalarda fonksiyonel bozukluklara, duygusal strese, yaşam kalitesinin düşmesine veya ölüme neden (Demir vd. 2013:105; Şen vd. 2013:17-18; Ersoy vd. 2014) olan bu enfeksiyonların oranı 1990'larda artmaya başlamıştır (Muto, 2000:275). Dünya çapında herhangi bir anda 1.4 milyondan fazla kişinin hastane enfeksiyonlarından etkilendiği düşünülmektedir (Allegranzi vd. 2007:116). Amerika Birleşik Devletlerinde 80.000 ölümün, Birleşik Krallıkta 5000 ölümün hastane enfeksiyonlarından kaynaklandığı tahmin edilmektedir (Erasmus vd. 2010:283). Avrupa'da, hastane enfeksiyon oranlarının ⒋4 ile ⒕8 arasında olduğu (Allegranzi vd. 2007:116), Birleşik Krallıkta o10 (Feather vd. 2000: 62), Türkiye'de de $\frac{0}{5}-15$ arasında değiştiği, yoğun bakım ünitelerinde ○20-30'a kadar çıktığı bildirilmektedir (Ersoy vd. 2014).

Kaynă̆ı; hastalar, ziyaretçiler, hastane personeli, tetkik ve tedavi amacıyla kullanılan aletler ile hastane ortamının kendisi olan (Terzi vd. 2009:8) hastane enfeksiyonları, hem çalışanlar hem de hastaneye başvuran veya tedavi olan hastalar için ciddi tehdit olarak görülmektedir (Erasmus vd. 2010:283; Jamal vd. 2012:171). Literatürde, enfeksiyon kontrolünün odak noktasının belirgin olarak değiştiği, artık dikkatin yalnızca hastalara değil, sağlık çalışanları ve diğer çalışanlara (temizlik çalışanları gibi) bulaşmaması üzerinde de yoğunlaştırmak gerektiği ileri sürülmektedir (Özvarış, 1999). Hem hastalar hem de sağlık çalışanları açısından önemi ortaya konan enfeksiyonlar ile ilgili olarak son ylllarda, hasta güvenliğine verilen önem giderek artmıştır. Dünya Sağlık Örgütü'nce yürütülen World Alliance for Patient Safety (Hasta Güvenliği Dünya İttifakı) çalışmasının hedeflerinden birisi hastane enfeksiyonlarının önemli ölçüde azaltılmasıdır (WHO, 2004; Erasmus vd. 2010). Bu hedef doğrultusunda hazırlanan eğitim programları ve geliştirilen uygulamalarla hastane enfeksiyonlarının yayılması sınırlandırılmaya çalışılmaktadır. Bu uygulamalardan biri de enfeksiyon kontrol uygulamalarıdır. Enfeksiyonları kontrol etmenin temel yapı taşlarından biri de hastane çalışanlarının uygun zamanda ellerini yıkamalarını sağlamaktır (Lankford vd. 2003:217). Hastane çalışanlarının ellerini uygun süre ve doğru teknik ile yıkamaları aynı zamanda onların karşı karşıya kaldıkları meslek risklerini de azaltmaktadır. Hem çalışanların sağlığı hem de hastane enfeksiyonlarının insidansını azaltmada önemli bir role sahip olan el yıkama davranışı Sağlık Bakanlığı tarafından da oldukça önemsenmiş, konu ile ilgili kongre, kurs, sempozyumlar aracılığı ile hastane çalışanlarına eğitimler verilmiş ve çalışanların bilgilendirilmesi ve farkındalıklarının artırılması hedeflenmiştir (Bilici vd. 2008; http: / /www.kalite.saglik.gov.tr/index.php?lang=tr\&page=192) .

El hijyeni (sabun ve su ile el yıkama veya dezenfektan kullanarak alkol bazlı el temizleme ürünleri vb.), hastane enfeksiyonları ve antimikrobiyal dirençli patojenlerin yayılmasını önlemek için en önemli yöntem olarak kabul edilmektedir (Erasmus vd. 2010:283). El hijyeninde, alkol bazlı el antiseptikleri kullanımı daha hızlı etki süresi, cildi su ve sabundan daha az tahriş etmesi nedeniyle yıllardır birçok Avrupa ülkesinde başarıyla kullanılmaktadır 
Tekingündüz, S., Kurt, A.Ö. ve Ayhan Temirci, H. Life Sciences (NWSALS), 4B0006, 2015; 10(4): 15-28

(Muto, 2000:275). Hastane enfeksiyonlarının önlenmesinde el hijyeninin en etkili yöntem olduğu bilinmesine rağmen (Ersoy vd. 2014), uyum davranışları tüm dünyada bir problem olarak görülmekte (Muto, 2000: 275; Pittet ve Donaldson, 2005:892; Erasmus vd. 2010:283) ve el yıkama işlemi sağlık çalışanları tarafından yeterli sıklıkta ve etkinlikte uygulanmadığı belirtilmektedir (Arda vd. 2005:183). Erasmus ve diğerlerinin (2010:287) yaptıkları sistematik incelemede, ortalama el hijyen uyumu $\% 40$ olarak bulunurken, en düşük el hijyen uyumunun hekimlerde (\%32), yoğun bakımlarda (\%30-\%40 arası) ve hastayla temastan önce (\%21) olduğu belirlenmiştir. Wendt ve diğerlerinin (2004:205) çalışmasında, el hijyen uyumunun, kliniklere oranla yoğun bakım birimleri gibi ünitelerde iş yoğunluğundan dolayı daha düşük düzeyde olduğu belirlenmiştir. Demir ve diğerlerinin (2013:107) çalışmasında el hijyenine uyum o19 olarak saptanmıştır. Hastane çalışanlarına enfeksiyon hastalıklarının bulaşması daha çok delicikesici aletlerle yaralanma, kontamine materyal ile temas, solunum yoluyla ve laboratuvar kaynaklı bulaş yoluyla olmaktadır.

Meslek hastalığı olarak kabul edilen, potansiyel olarak yaşamı tehdit etmekle beraber önlenebilen HBV, HCV ve HIV enfeksiyonlarının bulaşmasında esas yol delici-kesici alet yaralanmalarıdır (NIOHS, 2000:2; Korkmaz, 2008:30-31; Terzi vd. 2009:8). Amerika'da, kesin olmamakla birlikte sağlık çalışanları arasında yılda 600.000 ile 800.000 arasında delici-kesici alet kaynaklı yaralanma olduğu tahmin edilmektedir. Bu yaralanmaların yaklaşık yarısının kayıtıara geçmediği ileri sürülmektedir. Çoğu iğne batması ile ilgili yaralanmaların hemşirelerle ilgili olduğu bildirilse de, temizlik çalışanları, hekimler, laboratuar çalışanları ve diğer sağlık çalışanlarının da bu durumdan etkilendikleri belirtilmektedir (NIOHS, 2000:2) .

Hastane enfeksiyonlarının azaltılması amacıyla, kan ve diğer vücut sıvılarının, deri ile temasını azaltmak için kişisel koruyucuların (eldiven, maske, gözlük, önlük vb.) kullanılması önerilmektedir (Beltrami vd. 2000:765). Literatürde, eldiven kullanımının sağlık bakım alanlarında patojenlerin geçişini azalttığını gösteren çeşitli çalışmalar olduğu belirtilmektedir (Flores ve Pevalin, 2006). Temizlik çalışanlarına, görevlerini yerine getirirken almaları gereken eğitimlerin yeterince verilmediği (Balcı vd., 2005; Terzi vd., 2009; Deveci vd.,2010), kişisel koruyucu donanımların kullanımında eksiklikler olduğu (Kişioğlu vd., 2002; Terzi vd., 2009; Yamazhan vd., 2009; Deveci vd., 2010), yapılması gereken aşıların tamamlanmadığı (Balcı vd., 2005; Terzi vd., 2009 Ersoy vd., 2014) ve bunlardan dolayı sağlıklarının risk altında olduğu düşünülmektedir.

\section{2. ÇALIŞMANIN ÖNEMI (RESEARCH SIGNIFICANCE)}

Sağlık kurumları sağlık hizmetlerinin sunulduğu, farklı meslek gruplarının ekip olarak çalıştığı, örgütsel yapıların öne çıktığı ve buna ek olarak sağlık hizmeti almak üzere başvuran kişilerden oluşan bir organizasyondur. Bununla beraber hastaneler "İş Sağlığı ve Güvenliği Tebliği"ne göre çok tehlikeli sınıfta yer alan işyerleridir. Sağlık çalışanları görevleri sürecinde fiziksel, kimyasal, biyolojik, ergonomik, psikososyal ve elektriksel tehlikeler gibi birçok riskle karşı karşıyadır. Biyolojik tehlikeler aynı zamanda hem çalışanların kendileri hem de hizmet sundukları kişiler açısından bulaşıcı hastalık riskini artırabilmektedir. Ortaya çıkabilecek enfeksiyon hastalıkları işe devamsızlığa, verimliliğin düşmesine, işgücü kaybına, ek maliyetlere (tedavi masrafları vb.) neden olurken; çalışan açısından 
Tekingündüz, S., Kurt, A.Ö. ve Ayhan Temirci, H. Life Sciences (NWSALS), 4B0006, 2015; 10(4): 15-28

ise hayatı tehdit eden durumlara, yaşam kalitesinin düşmesine, dışlanmaya, sosyal çevreden uzaklaşmaya yol açabilmektedir. Çalışmada, Ankara'da bir eğitim ve araştırma hastanesinde görev yapan temizlik iş̧̧ilerinin çalışma ortamından kaynaklı bulaşıcı hastalık risk ve uygulamalarının değerlendirilmesi amaçlanmıştır. Çalışma sadece kamuda bir eğitim ve araştırma hastanesinde gerçekleştirilmiş ve araştırma grubu sadece 270 gönüllüden oluşmuştur. Dolayısıyla sonuçların genellenmesi mümkün değildir. Bir diğer sınırlılık ta araştırmada sadece anket uygulanmış olup, gözleme dayalı herhangi bir çalışma yapılmamıştır.

\section{GEREÇ VE YÖNTEM (MATERIAL AND METHOD)}

Çalışma, Ankara'da kamuya ait bir eğitim ve araştırma hastanesinde gerçekleştirilmiştir. Hastane, 1109 fiili yatağa sahip, 30 dalda hizmet, 25 dalda eğitim veren Türkiye'nin en büyük eğitim ve araştırma hastanelerinden birisidir. Kesitsel tipteki bu araştırmanın verileri 1-29 Şubat 2012 tarihleri arasında toplanmıştır. Araştırma grubunu oluşturan 650 kişilik temizlik çalışanından 270'i (\%42) çalışmaya gönülıü olarak katılmıştır. Çalışanların büyük kısmı ameliyathane, yoğun bakım ve kliniklerde görev yapmaktadır. Çalışanlar işe başlamadan önce görev yaptığı birime özgü uyum eğitimleri almaktadırlar. Gönüllülük ilkesi esas alınarak gerçekleştirilen bu çalışmada araştırma ekibi tarafından katılımcılara araştırma ve anket hakkında gerekli bilgilendirmede bulunulmuş ve yüz yüze görüşme yöntemi ile anket uygulanmıştır. Ankette kişisel özellikleri içeren soruların yanında, çalışanların kişisel koruyucu kullanma durumları, iğne batması durumunda aldıkları tutumları, el yıkama konusundaki tutumları, el yıkama alışkanlıkları ve işe girmeden önce birimi ile ilgili eğitim alma durumları gibi çalışma yaşamını irdeleyen sorular yer almaktaydı.

Araştırmada çalışanların iğne batması durumunda iğne batan bölgeyi su ve sabun ile yıkaması, enfeksiyon kontrol komitesine ya da enfeksiyon hastalıkları uzmanına başvurması "doğru", hiçbir şey yapmaması ve fikrim yok yanıtları ise "yanıış" tutum olarak değerlendirildi. Araştırmanın bă̆ımlı değişkenleri: iğne batması halinde gösterilen tutum ile el yıkama konusunda gösterilen tutumlar; bağımsız değişkenleri ise; cinsiyet, medeni durum, çocuk sahipliği, öğrenim düzeyi, çalışılan birim, hizmet süresi, işe giriş muayenesi, aralıklı kontrol muayenesi, hijyen ve bulaşıcı hastalık eğitimi alma durumu olarak belirlenmiştir. Veriler bilgisayar ortamına aktarılmış, verilerin özetlenmesinde tanımlayıcı istatistikler, analizinde Ki-Kare Testi kullanılmış, p değeri $<0.05$ olarak alınmıştır.

\section{BULGULAR (FINDINGS)}

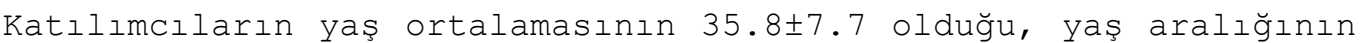
da 19 ile 59 arasında olduğu belirlenmiştir. İşçilerin o61.5'i erkek, ○77.4'ü evli, 65.9'u çocuk sahibi, \%53'ü ilkokul mezunu olduğu saptanmıştır. Katılımcıların o64.1'inin yataklı servislerde çalıştığı, o89.3'ünün hizmet süresinin bir yıl ve daha üzeri olduğu, 89.6'sının işe giriş muayenesinin, o73'ünün aralıklı kontrol muayenesinin yapıldığı, o74.1'inin hijyen ve bulaşıcı hastalıklar konusunda eğitim aldığı saptanmıştır. Katılımcıların $\% 87.4$ 'ünün çalışma yerinden memnun (memnun ve çok memnun) olduğu belirlenmiştir. Katılımcıların ㅇ‥4'ünün mesleğine devam etmek istediği belirlenmiştir (Tablo 1). 
Tekingündüz, S., Kurt, A.Ö. ve Ayhan Temirci, H. Life Sciences (NWSALS), 4B0006, 2015; 10(4): 15-28

Tablo 1. Temizlik işçilerinin kişisel özellikleri (Table 1. Cleaning workers personnel characteristics)

\begin{tabular}{|c|c|c|c|}
\hline & & $\mathrm{n}$ & $\frac{\circ}{\circ}$ \\
\hline Cinsiyet & Kadın & 104 & 38.5 \\
\hline \multirow[b]{2}{*}{ Medeni Durum } & Evli & 209 & 77.4 \\
\hline & Bekâr & 61 & 22.6 \\
\hline \multirow{2}{*}{ Çocuk Durumu } & Çocuk var & 178 & 65.9 \\
\hline & Çocuksuz & 92 & 34.1 \\
\hline \multirow{3}{*}{ Öğrenim Düzeyi } & İlkokul & 143 & 53.0 \\
\hline & Ortaokul & 63 & 23.3 \\
\hline & Lise ve üzeri & 64 & 23.7 \\
\hline \multirow{3}{*}{ Çalıştığı Birim } & Yataklı servis & 173 & 64.1 \\
\hline & Poliklinik & 43 & 15.9 \\
\hline & İdari birimler & 54 & 20.0 \\
\hline \multirow{2}{*}{ Hizmet Süresi } & $0-365$ gün & 29 & 10.7 \\
\hline & 1 yıl ve üzeri & 241 & 89.3 \\
\hline \multirow{2}{*}{ İşe Giriş Muayenesi } & Yapılmış & 242 & 89.6 \\
\hline & Yapılmamış & 28 & 10.4 \\
\hline \multirow{2}{*}{ Aralıklı Kontrol Muayenesi } & Yapılmış & 197 & 73.0 \\
\hline & Yapılmamış & 73 & 27.0 \\
\hline \multirow{2}{*}{ Hijyen, Bulaşıcı Hastalık Eğitimi } & Evet & 200 & 74.1 \\
\hline & Hayır & 70 & 25.9 \\
\hline \multirow{2}{*}{ Kendisine Ait Elbise Dolabı } & Var & 250 & 92.6 \\
\hline & Yok & 20 & 7.4 \\
\hline \multirow{3}{*}{ Çalışma Yeri Memnuniyeti } & Çok memnun & 88 & 32.6 \\
\hline & Memnun & 148 & 54.8 \\
\hline & Memnun değil & 34 & 12.6 \\
\hline \multirow{2}{*}{ Mesleğe Devam Etme } & Evet & 236 & 87.4 \\
\hline & Hayır & 34 & 12.6 \\
\hline
\end{tabular}

Çalışanların ⒏ı'inin iş önlüğü-formayı hiç kullanmadığı ya da bazen kullandığı, o4.9'unun eldiveni hiç kullanmadığı ya da bazen kullandığı, 36.6'sının bone-şapka hiç kullanmadığı ya da bazen kullandığı, o28.1'inin maske hiç kullanmadığı ya da bazen kulıandığı, o67.8'inin gözlüğü hiç kullanmadığı ya da bazen kullandığı saptanmıştır (Tablo 2) .

Tablo 2. Kişisel koruyucu kullanımı

(Table 2. Personal protective use)

\begin{tabular}{|l|c|c|c|c|c|c|c|c|}
\hline \multirow{2}{*}{$\begin{array}{l}\text { Kişisel } \\
\text { Koruyucular }\end{array}$} & \multicolumn{2}{|c|}{$\begin{array}{c}\text { Hiç } \\
\text { Kullanmama }\end{array}$} & \multicolumn{2}{c|}{$\begin{array}{c}\text { Bazen } \\
\text { Kullanma }\end{array}$} & \multicolumn{2}{c|}{$\begin{array}{c}\text { Her Zaman } \\
\text { Kullanma }\end{array}$} & \multirow{2}{*}{ Toplam } & \multirow{2}{*}{} \\
\cline { 2 - 9 } & $\mathrm{n}$ & $\frac{\circ}{\circ}$ & $\mathrm{n}$ & $\frac{\circ}{\circ}$ & $\mathrm{n}$ & $\frac{\circ}{\circ}$ & & \\
\hline İş Önlüğü-Forma & 12 & 4.4 & 10 & 3.7 & 248 & 91.9 & 270 & 100 \\
\hline Eldiven & 8 & 3.0 & 5 & 1.9 & 257 & 95.1 & 270 & 100 \\
\hline Bone-Şapka & 56 & 20.7 & 43 & 15.9 & 171 & 63.4 & 270 & 100 \\
\hline Maske & 19 & 7.0 & 57 & 21.1 & 194 & 71.9 & 270 & 100 \\
\hline Gözlük & 150 & 55.6 & 33 & 12.2 & 87 & 32.2 & 270 & 100 \\
\hline
\end{tabular}

Aşağıda Tablo 3'te görüldüğü üzere katılımcıların o51.9'unun iğne batması durumunda yanlış tutum sergiledikleri görülmektedir. İğne batması durumunda sergilenen tutumun, sosyo-demografik özellikler (cinsiyet, medeni durum, çocuk sahibi olup olmama, öğrenim düzeyi, hizmet süresi) ve işe giriş muayenesi, aralıklı kontrol muayenesi, hijyen ve bulaşıcı hastalıklar konusunda eğitimi alması ile 
Tekingündüz, S., Kurt, A.Ö. ve Ayhan Temirci, H. Life Sciences (NWSALS), 4B0006, 2015; 10(4): 15-28

değişmediği saptanmıştır. Yapılan istatistiksel analizde anlamlı farklılık bulunmamıştır ( $>0.05)$.

Tablo 3. Temizlik işçilerinin iğne batması durumunda tutumları

(Table 3. In case of needle-stick attitude of cleaning workers)

\begin{tabular}{|c|c|c|c|c|c|c|c|c|c|}
\hline & \multicolumn{2}{|c|}{ Yanlış } & \multicolumn{2}{|c|}{ Doğru } & \multicolumn{2}{|c|}{ Toplam } & \multirow[t]{2}{*}{$x^{2}$} & \multirow[t]{2}{*}{$\mathrm{p}$} \\
\hline & & $\mathrm{n}$ & $\frac{\circ}{0}$ & $\mathrm{n}$ & $\frac{\circ}{0}$ & $\mathrm{n}$ & $\frac{\circ}{0}$ & & \\
\hline Cinsiyet & $\begin{array}{l}\text { Kadın } \\
\text { Erkek }\end{array}$ & $\begin{array}{l}48 \\
92\end{array}$ & $\begin{array}{l}46.2 \\
55.4\end{array}$ & $\begin{array}{l}56 \\
74\end{array}$ & $\begin{array}{l}53.8 \\
44.6\end{array}$ & $\begin{array}{l}104 \\
166\end{array}$ & $\begin{array}{l}100 \\
100\end{array}$ & 2.200 & 0.138 \\
\hline $\begin{array}{l}\text { Medeni } \\
\text { Durumu }\end{array}$ & $\begin{array}{c}\text { Evli } \\
\text { Bekâr }\end{array}$ & $\begin{array}{c}104 \\
36\end{array}$ & $\begin{array}{l}49.8 \\
59.0\end{array}$ & $\begin{array}{c}105 \\
25\end{array}$ & $\begin{array}{l}50.2 \\
41.0\end{array}$ & $\begin{array}{c}209 \\
61\end{array}$ & $\begin{array}{l}100 \\
100\end{array}$ & 1.620 & 0.203 \\
\hline $\begin{array}{c}\text { Çocuk } \\
\text { Durumu }\end{array}$ & $\begin{array}{l}\text { Çocuk var } \\
\text { Çocuksuz }\end{array}$ & $\begin{array}{l}86 \\
54\end{array}$ & $\begin{array}{l}48.3 \\
58.7\end{array}$ & $\begin{array}{l}92 \\
38\end{array}$ & $\begin{array}{l}51.7 \\
41.3\end{array}$ & $\begin{array}{c}178 \\
92\end{array}$ & $\begin{array}{l}100 \\
100\end{array}$ & 2.618 & 0.106 \\
\hline $\begin{array}{l}\text { Öğrenim } \\
\text { Düzeyi }\end{array}$ & $\begin{array}{c}\text { İlkokul } \\
\text { Ortaokul } \\
\text { Lise ve } \\
\text { Üzeri }\end{array}$ & $\begin{array}{l}70 \\
40 \\
30\end{array}$ & $\begin{array}{l}49.0 \\
63.5 \\
46.9\end{array}$ & $\begin{array}{l}73 \\
23 \\
34\end{array}$ & $\begin{array}{l}51.0 \\
36.5 \\
53.1\end{array}$ & $\begin{array}{c}143 \\
63 \\
64\end{array}$ & $\begin{array}{l}100 \\
100 \\
100\end{array}$ & 4.536 & 0.104 \\
\hline $\begin{array}{c}\text { Çalıştığı } \\
\text { Birim }\end{array}$ & $\begin{array}{c}\text { Yataklı } \\
\text { Servis } \\
\text { Poliklinik } \\
\text { İdari } \\
\text { Birimler }\end{array}$ & $\begin{array}{l}88 \\
29 \\
23\end{array}$ & $\begin{array}{l}50.9 \\
67.4 \\
42.6\end{array}$ & $\begin{array}{l}85 \\
14 \\
31\end{array}$ & $\begin{array}{l}49.1 \\
32.6 \\
57.4\end{array}$ & $\begin{array}{c}173 \\
43 \\
54\end{array}$ & $\begin{array}{l}100 \\
100 \\
100\end{array}$ & 6.108 & 0.047 \\
\hline $\begin{array}{l}\text { Hizmet } \\
\text { Süresi }\end{array}$ & $\begin{array}{c}\text { 0-365 Gün } \\
1 \text { Yıl ve } \\
\text { Üzeri }\end{array}$ & $\begin{array}{c}15 \\
125\end{array}$ & $\begin{array}{l}51.7 \\
51.9\end{array}$ & $\begin{array}{c}14 \\
116\end{array}$ & $\begin{array}{l}48.3 \\
48.1\end{array}$ & $\begin{array}{c}29 \\
241\end{array}$ & $\begin{array}{l}100 \\
100\end{array}$ & 0.001 & 0.988 \\
\hline $\begin{array}{l}\text { İşe Giriş } \\
\text { Muayenesi }\end{array}$ & $\begin{array}{c}\text { Yapılmış } \\
\text { Yapılmamış }\end{array}$ & $\begin{array}{c}124 \\
16\end{array}$ & $\begin{array}{l}51.2 \\
57.1\end{array}$ & $\begin{array}{c}118 \\
12\end{array}$ & $\begin{array}{l}48.8 \\
42.9\end{array}$ & $\begin{array}{c}242 \\
28\end{array}$ & $\begin{array}{l}100 \\
100\end{array}$ & 0.350 & 0.554 \\
\hline $\begin{array}{c}\text { Aralıklı } \\
\text { Kontrol } \\
\text { Muayenesi }\end{array}$ & $\begin{array}{c}\text { Yapılmış } \\
\text { Yapılmamış }\end{array}$ & $\begin{array}{c}102 \\
38\end{array}$ & $\begin{array}{l}51.8 \\
52.1\end{array}$ & $\begin{array}{l}95 \\
35\end{array}$ & $\begin{array}{l}48.2 \\
47.9\end{array}$ & $\begin{array}{c}197 \\
73\end{array}$ & $\begin{array}{l}100 \\
100\end{array}$ & 0.002 & 0.968 \\
\hline $\begin{array}{l}\text { Hijyen, } \\
\text { Bulaşıcı } \\
\text { Hastalık } \\
\text { Eğitimi }\end{array}$ & $\begin{array}{l}\text { Evet } \\
\text { Hayır }\end{array}$ & $\begin{array}{l}99 \\
41\end{array}$ & $\begin{array}{l}49.5 \\
58.6\end{array}$ & $\begin{array}{c}101 \\
29\end{array}$ & $\begin{array}{l}50.5 \\
41.4\end{array}$ & $\begin{array}{c}200 \\
70\end{array}$ & $\begin{array}{l}100 \\
100\end{array}$ & 1.709 & 0.191 \\
\hline \multicolumn{2}{|c|}{ Toplam } & 140 & 51.9 & 130 & 48.1 & 270 & 100 & & \\
\hline
\end{tabular}

Çalışmamızda iğne batması durumunda sergilenen doğru/yanlış tutumun sadece temizlik iş̧̧ilerinin çalıştığı birime göre istatistiksel anlamlı farklılık gösterdiği saptanmıştır $(p<0.05)$. Poliklinik çalışanlarında iğne batması durumunda doğru tutum belirleyenlerin oranı ㅇ․6, yataklı servislerde 49.1 ve idari birimde 57.4 olarak belirlenmiştir. Çalışmada ayrıca, katılımcıların 10’u (\%3.7) çalışırken delici kesici alet yaralanması sonucu iş kazası geçirdiği saptanmıştır.

Tablo 4'te gözlendiği üzere el yıkama sorusuna yanıt veren katılımcıların 81.3'ü işe başlarken, 96.2'si iş bitiminde, \%97.2'si tuvaletten çıkınca, \%96.8'i eline bir şey bulaşınca, \% 93.4'ü eve giderken, o97.2'si lavaboyu temizledikten sonra, \%97.7'si de çöpleri topladıktan sonra ellerini mutlaka yıkadıklarını belirtmiştir. Çalışanların \%4.4'ünün ellerini yıkarken "sadece su" kullanarak yanlış tutum sergiledikleri ve el ylkama tutumunun sosyo-demografik özellikler (cinsiyet, medeni durum, çocuk sahibi olup olmama, öğrenim düzeyi, çalıştığı birim, hizmet süresi), işe giriş muayenesi, aralıklı 
Tekingündüz, S., Kurt, A.Ö. ve Ayhan Temirci, H.

Life Sciences (NWSALS), 4B0006, 2015; 10(4): 15-28

kontrol muayenesi, hijyen ve bulaşıcı hastalıklar eğitimiyle değişmediği ve yapılan istatistiksel analizde anlamlı farklılık olmadığı saptanmıştır (p>0.05) (Tablo 5).

Temizlik işçilerinin o3.7'sinin ellerini yıkaması gereken 10 işlemin hiçbirinde elini yıkamadığı saptanmıştır. Çalışanların \%58.9' unun bu 10 işlemin hepsinde el yıkadığı ve o15.2'sinin de dokuz işlemde el yıkadığı belirlenmiştir (Tablo 6) .

Tablo 4. Temizlik iş̧̧ilerinin el yıkama alışkanlıkları

(Table 4. Handwashing habits of cleaning workers)

\begin{tabular}{|c|c|c|c|c|c|c|c|c|}
\hline & \multicolumn{2}{|c|}{$\begin{array}{c}\text { Hiç } \\
\text { Yıkamayan }\end{array}$} & \multicolumn{2}{|c|}{$\begin{array}{c}\text { Bazen } \\
\text { yıkayan }\end{array}$} & \multicolumn{2}{|c|}{$\begin{array}{l}\text { Mutlaka } \\
\text { Yıkayan }\end{array}$} & \multirow[t]{2}{*}{ Top. } & \multirow[t]{2}{*}{$\%$} \\
\hline & $\mathrm{n}$ & $\%$ & $\mathrm{n}$ & $\%$ & $\mathrm{n}$ & $\%$ & & \\
\hline İşe başlarken & 7 & 3.0 & 36 & 15.7 & 187 & 81.3 & 230 & 100 \\
\hline İş bitince & 8 & 3.0 & 2 & 0.8 & 255 & 96.2 & 265 & 100 \\
\hline Yemekten önce & 6 & 2.0 & 7 & 3.0 & 245 & 95.0 & 258 & 100 \\
\hline Yemekten sonra & 4 & 1.6 & 14 & 5.6 & 232 & 92.8 & 250 & 100 \\
\hline Tuvalete girmeden önce & 12 & 4.9 & 34 & 14.0 & 197 & 81.1 & 243 & 100 \\
\hline Tuvaletten çıkınca & 4 & 1.6 & 3 & 1.2 & 251 & 97.2 & 258 & 100 \\
\hline Ele bir şey bulaşınca & 4 & 1.6 & 4 & 1.6 & 249 & 96.8 & 257 & 100 \\
\hline Eve giderken & 6 & 2.3 & 11 & 4.3 & 241 & 93.4 & 258 & 100 \\
\hline Lavabo temizliğinden sonra & 4 & 1.6 & 3 & 1.2 & 251 & 97.2 & 258 & 100 \\
\hline Çöplerin toplanmasından sonra & 4 & 1.5 & 2 & 0.8 & 254 & 97.7 & 260 & 100 \\
\hline Tuvaletlerin temizliğinden sonra & 4 & 1.5 & 2 & 0.8 & 254 & 97.7 & 260 & 100 \\
\hline
\end{tabular}

Tablo 5. El Yıkama konusunda çalışanların tutumları

(Table 5. Attitudes of employees about hand washing)

\begin{tabular}{|c|c|c|c|c|c|c|c|c|c|}
\hline & & \multicolumn{2}{|c|}{$\begin{array}{l}\text { Sadece } \\
\text { Su İle }\end{array}$} & \multicolumn{2}{|c|}{$\begin{array}{c}\text { Sabunlu Su } \\
\text { İle }\end{array}$} & \multicolumn{2}{|c|}{ Toplam } & \multirow[t]{2}{*}{$x^{2}$} & \multirow[t]{2}{*}{$\mathrm{p}$} \\
\hline & & $\mathrm{n}$ & $\frac{\circ}{0}$ & $\mathrm{n}$ & $\frac{\circ}{0}$ & $\mathrm{n}$ & $\frac{\circ}{0}$ & & \\
\hline \multirow{2}{*}{ Cinsiyet } & Kadın & 7 & 6.7 & 97 & 93.3 & 104 & 100 & \multirow[t]{2}{*}{2.082} & \multirow[t]{2}{*}{0.149} \\
\hline & Erkek & 5 & 3.0 & 161 & 97.0 & 166 & 100 & & \\
\hline \multirow{2}{*}{$\begin{array}{l}\text { Medeni } \\
\text { Durum }\end{array}$} & Evli & 12 & 5.7 & 197 & 94.3 & 209 & 100 & \multirow{2}{*}{3.665} & \multirow{2}{*}{0.056} \\
\hline & Bekâr & 0 & 0.0 & 61 & 00.0 & 61 & 100 & & \\
\hline \multirow{2}{*}{$\begin{array}{l}\text { Çocuk } \\
\text { Durumu }\end{array}$} & Çocuk var & 10 & 5.6 & 168 & 94.4 & 178 & 100 & \multirow[t]{2}{*}{1.694} & \multirow[t]{2}{*}{0.193} \\
\hline & Çocuksuz & 2 & 2.2 & 90 & 97.8 & 92 & 100 & & \\
\hline \multirow{3}{*}{$\begin{array}{l}\text { Öğrenim } \\
\text { Düzeyi }\end{array}$} & İlkokul & 10 & 7.0 & 133 & 93.0 & 143 & 100 & \multirow{3}{*}{5.403} & \multirow{3}{*}{0.067} \\
\hline & Ortaokul & 2 & 3.2 & 61 & 96.8 & 63 & 100 & & \\
\hline & Lise ve Üzeri & 0 & 0.0 & 64 & 100.0 & 64 & 100 & & \\
\hline \multirow{3}{*}{$\begin{array}{l}\text { Çalıştığı } \\
\text { Birim }\end{array}$} & Yataklı Servis & 6 & 3.5 & 167 & 96.5 & 173 & 100 & \multirow{3}{*}{1.509} & \multirow{3}{*}{0.470} \\
\hline & Poliklinik & 2 & 4.7 & 41 & 95.3 & 43 & 100 & & \\
\hline & İdari Birimler & 4 & 7.4 & 50 & 92.6 & 54 & 100 & & \\
\hline \multirow{2}{*}{$\begin{array}{l}\text { Hizmet } \\
\text { Süresi }\end{array}$} & $0-365$ Gün & 0 & 0.0 & 29 & 100.0 & 29 & 100 & \multirow{2}{*}{1.511} & \multirow{2}{*}{0.219} \\
\hline & 1 Yıl ve Üzeri & 12 & 5.0 & 229 & 95.0 & 241 & 100 & & \\
\hline \multirow{2}{*}{$\begin{array}{l}\text { İşe Giriş } \\
\text { Muayenesi }\end{array}$} & Yapılmış & 11 & 4.5 & 231 & 95.5 & 242 & 100 & \multirow{2}{*}{0.056} & \multirow{2}{*}{0.813} \\
\hline & Yapılmamış & 1 & 3.6 & 27 & 96.4 & 28 & 100 & & \\
\hline \multirow{2}{*}{$\begin{array}{l}\text { Aralıklı } \\
\text { Kontrol } \\
\text { Muayenesi }\end{array}$} & Yapılmış & 11 & 5.6 & 186 & 94.4 & 197 & 100 & \multirow[b]{2}{*}{2.227} & \multirow[b]{2}{*}{0.136} \\
\hline & Yapılmamış & 1 & 1.4 & 72 & 98.6 & 73 & 100 & & \\
\hline \multirow{2}{*}{$\begin{array}{l}\text { Hijyen, } \\
\text { Bulaşıcı } \\
\text { Hastalık } \\
\text { Eğitimi }\end{array}$} & Evet & 11 & 5.5 & 189 & 94.5 & 200 & 100 & \multirow[t]{2}{*}{2.024} & \multirow[t]{2}{*}{0.155} \\
\hline & Hayır & 1 & 1.4 & 69 & 98.6 & 70 & 100 & & \\
\hline \multicolumn{2}{|l|}{ Toplam } & 12 & 4.4 & 258 & 95.6 & 270 & 100 & & \\
\hline
\end{tabular}


Tekingündüz, S., Kurt, A.Ö. ve Ayhan Temirci, H. Life Sciences (NWSALS), 4B0006, 2015; 10(4): 15-28

Tablo 6. Çalışanların el yıkama alışkanlıklarının dă̆ılımı (Table 6. The distribution of employees hand washing habits)

\begin{tabular}{|c|c|c|c|}
\hline \multirow{13}{*}{$\begin{array}{l}\text { El Yıkamanın } \\
\text { Gerekli Olduğu } \\
\text { İşlemler }\end{array}$} & Açıklama & $\mathrm{n}$ & $\frac{\circ}{0}$ \\
\hline & El yıkamayanlar & 10 & 3.7 \\
\hline & Sadece bir işlemde & 4 & 1.5 \\
\hline & Sadece iki işlemde & 1 & 0.4 \\
\hline & Sadece üç işlemde & 1 & 0.4 \\
\hline & Sadece dört işlemde & 2 & 0.7 \\
\hline & Sadece beş işlemde & 2 & 0.7 \\
\hline & Sadece altı işlemde & 3 & 1.1 \\
\hline & Sadece yedi işlemde & 19 & 7.0 \\
\hline & Sadece sekiz işlemde & 28 & 10.4 \\
\hline & Sadece dokuz işlemde & 41 & 15.2 \\
\hline & Sadece on işlemde & 159 & 58.9 \\
\hline & Toplam & 270 & 100.0 \\
\hline
\end{tabular}

Yapılan bu araştırmada, çalışanların \%33.7'sinin sadece Hepatit B, \%6.3'ünün sadece tetanoz, \%46.7'sinin de her iki aşıyı yaptırdı ğı, ancak o13.3'ünün bu aşıları hiç yaptırmadığı saptanmıştır. Ayrıca çalışmada, temizlik çalışanlarının \%48.1'i kendisinden hastalara hastalık bulaşabileceğini, 52.6'sı hastadan hastaya hastalık bulaştırabileceğini düşünmekteydi.

\section{SONUÇ VE TARTIŞMA (CONCLUSION AND DISCUSSION)}

Ankara'da bir eğitim ve araştırma hastanesinde görevli temizlik çalışanlarının çalışma ortamından kaynaklı bulaşıcı hastalık risk ve uygulamalarının değerlendirildiği bu çalışmada, katılımcıların yaklaşık dörtte üçü (\%74.1) hijyen ve bulaşıcı hastalıklar konusunda eğitim aldığını bildirmişlerdir. Terzi ve diğerlerinin çalışmasında (2009:9-10) temizlik çalışanlarının 65.4'ünün kişisel hijyen, \%57.1'inin hastane enfeksiyonları ve korunma yolları, \%26.8'inin de bulaşıcı hastalıklar ve korunma yolları konularında eğitim aldıkları belirlenmiştir. Balcı ve diğerlerinin (2005:161) çalışmasında da temizlik çalışanlarının işe başlamadan önce temizlik, hijyen ve bulaşıcı hastalıklar konusunda eğitim alma oranı \%48.6ロbulunmuştur. Deveci ve diğerlerinin (2010:123) çalışmasında, temizlik çalışanlarında, hijyen kuralları ve bulaşıcı hastalıklar eğitimi alanların oranı o43.8 olarak bildirilmiştir. Araştırmada elde edilen bulguların, diğer çalışmaların bulgularından daha yüksek olduğu görülmesine rağmen eğitim alan temizlik işçisi oranının yetersiz olduğu düşünülmekte ve çalışanların tamamının eğitim almış olması beklenmektedir.

Kişisel koruyucuların kullanılması, çalışanların hem kendilerini, hem çalışma ortamındaki hastaları hem de dolaylı enfeksiyon riskinden aile bireylerini enfeksiyonlardan korumaları açısından oldukça önemlidir. Hastane yönetimlerinin bunların neden olduğu işgücü kaybını da göz önüne alarak çalışanlara özellikle bu malzemelerin kullanılması konusunda eğitimler düzenlemesinin, mesai süresince çalışanların bu koruyucuları kullanıp kullanmadıklarını gözlemesinin önemli olduğu düşünülmektedir. Literatürde (Flores ve Pevalin, 2006) eldiven kullanımının sağlık bakım alanlarında patojen mikroorganizmaların geçişini azalttığını gösteren çeşitıi çalışmalar olduğu belirtilmektedir. Yapılan bu çalışmada, temizlik çalışanların \%8.1'inin iş önlüğü-formayı hiç ya da bazen kullandığı, o4.9'unun eldiveni hiç ya da bazen kullandığı, ঃ36.6'sının bone-şapka hiç ya da bazen kullandığı, 28.1'inin maske hiç ya da bazen kullandığı 
Tekingündüz, S., Kurt, A.Ö. ve Ayhan Temirci, H. Life Sciences (NWSALS), 4B0006, 2015; 10(4): 15-28

saptanmıştır. Deveci ve diğerlerinin (2010:123) çalışmasında, çalışanların \%11.6'sının bone/başlık, \%8.9'unun maske, \%100'ünün eldiven kullandığını bildirmiştir. Terzi ve diğerlerinin (2009:9) çalışmasında çalışanlarının o77.5'inin maskeyi kullanmadığı veya nadiren kullandığı, o15.8'inin de "genellikle" kullandığı belirlenmiştir. Yamazhan ve diğerlerinin (2009:79) yoğun bakımda çalışan temizlik elemanları ile yaptıkları çalışmada, el hijyen kurallarına uyumun o80.8 olduğu, eldiven kullanım oranının da \%90.4 olduğu belirlenmiştir. Kişioğlu ve diğerlerinin (2002:392) çalışmasında, işlemler sırasında her zaman eldiven giyme oranı 52.4, eldiven giymeden önce ve sonra el yıkama alışkanlığı da o30.4 olarak belirlenmiştir. Merih ve diğerlerinin (2009:13) çalışmasında, sağlık çalışanlarının o59.6'sının koruyucu bariyer kullanmasına rağmen yaralandığı belirlenmiştir. Yukarıdaki verilerden de anlaşıldığı üzere, araştırmamızda ve Türkiye'de kişisel koruyucu kullanma oranının yetersiz olduğu söylenebilir.

Flores ve Pevalin'in (2006) çalışmasında, gerekli durumda eldiven kullanan doktorların oranı \%71 iken, bu oran hemşirelerde \%92, diğer yardımcı sağlık personelinde :100 olarak belirtilmiştir. Genel olarak sağlık çalışanlarında gerekli eldiven kullanım oranı da \%92 oranındadır. Aynı çalışmada, el hijyenine uyum oranı hekimlerde $\% 50$ iken, hemşirelerde 69, diğer yardımcı sağlık personelinde de 58 oranındadır. Genel el hijyen uyum oranı ise $\% 64$ olarak belirlenmiştir. Meslek açısından fark anlamlı bulunmamıştır.

Araştırmada, temizlik elemanlarının o51.9'unun iğne batması durumunda yanlış tutum sergiledikleri belirlenmiştir. Çalışmada iğne batması durumunda sergilenen tutum ile sadece çalıştığı birim arasında istatistiksel anlamlı fark bulunması önemlidir. Risk durumunun yüksek olduğu yataklı servislerde iğne batması durumunda doğru tutum belirleyenlerin oranı 49.1 iken polikliniklerde bu oran \%32.6'dir. Risk oranın en düşük olduğu idari birimde doğru tutum belirleyenlerin oranı 57.4 olarak belirlenmiştir. Çalışılan birimin enfeksiyon riski arttıkça iğne batması durumunda doğru tutumun artması beklenmekte iken, araştırma sonuçları bunun tam tersi çıkmıştır. Bu durum yüksek riskli birimde çalışan işçilerin enfeksiyon bulaşma riskinin yüksek olduğunu düşündürmektedir.

Çalışmada, iğne batması sonrası gösterilen tutum ile ilgili olarak, hijyen ve bulaşıcı hastalıklar konusunda eğitim alanlarla eğitim almayanlar arasındaki farkın anlamlı çıkmamasının nedeni, verilen eğitimlerin etkin olmamasına diğer bir deyişle nitelikli olmamasına bağlanabilir. Bu nedenle hijyen ve bulaşıcı hastalıklardan korunma konusunda verilen eğitim program içeriklerinin yeniden gözden geçirilmesi, niteliğinin artırılması ve eğitimin düzenli olarak yinelenmesinin eğitimin sonucuna olumlu katkılar sunacağı düşünülmektedir.

Terzi ve diğerlerinin çalışmasında (2009:9), çalışanların ○27.8'i hastane ortamında çalışma sırasında en az bir kez delicikesici bir aletle yaralandığını belirtmişlerdir. Altıok ve diğerlerinin (2009:74) çalışmasında, sağlık çalışanlarının o79.1'inin çalışma hayatında en az bir kez delici-kesici aletle yaralandığı, yaralanmaların \%60.9' unun kanla bulaşmış aletle ve çoğunlukla enjektör iğnesi ile yaşandığı (\%89.2) belirlenmiştir. Omaç ve diğerlerinin (2010:21) çalışmasında, hemşirelerin \%62.7'sinin son üç ay içerisinde en az bir kez delici-kesici yaralanma geçirdikleri belirlenmiştir. Kürtünlü'nün (2013:1) ameliyathane çalışanları ile olan çalışmasında, cerrahların tamamının, hemşirelerin \%86,9'sının, temizlik 
Tekingündüz, S., Kurt, A.Ö. ve Ayhan Temirci, H. Life Sciences (NWSALS), 4B0006, 2015; 10(4): 15-28

çalışanlarının o80'inin ve sterilizasyon çalışanlarının \%40'ının en az bir kere cerrahi aletlerle yaralanma olayı yaşadığı saptanmıştır. Ersoy ve diğerlerinin (2014) çalışmasında, delici-kesici aletle yaralandıklarını ifade edenlerin oranı 33.1 çıkmıştır. Merih ve diğerlerinin (2009:14) çalışmasında, delici-kesici alet yaralanmalarının en fazla temizlik personellerinde görüldüğü belirtilmiştir. Araştırma sonuçları da temizlik işçilerinin o3.7'sinin iş kazası geçirerek delici kesici alet yaralanması yaşaması göz önüne alınınca yapılan işin yüksek riskli olduğu net olarak ortaya çıkmaktadır.

Ergönül ve diğerlerinin (1999:177) çalışmasında, şüpheli infekte bir iğne battığında ilk ne yaparsınız sorusuna "temas eden bölgeyi sabunla, alkolle veya antiseptikle yıkarım" yanıtı verenlerin oranı ○36.4, "immunglobulin, profilaksi gibi ileri önlemler için enfeksiyon hastalıkları bölümüne başvururum" yanıtı verenlerin oranı $\% 32.8$ olarak ifade edilmiştir. Çalışmamızda da temizlik işçilerinin ancak yarısının iğne batması durumunda doğru tutum belirleyebilmesi çalışanların bulaşıcı hastalık riskini iyice artırmaktadır.

Çalışmada, temizlik çalışanlarının el yıkama tutumlarının, sosyo-demografik özellikler, işe giriş muayenesi, aralıklı kontrol muayenesi, hijyen ve bulaşıcı hastalıklar eğitimi ile değişmemesinin nedeni; eğitimlerin etkin olmamasından kaynaklanmış olabileceği düşünülmektedir. Ayrıca çalışmada, temizlik çalışanlarının \%94.4'ü her iş bitiminde, \%92.2'si eline bir şey bulaştıktan sonra, \%89.3'ü iş çıkışı (eve gidince), 이고 si yemekten önce mutlaka ellerini yıkadığını belirtmiştir. Yapılan bu çalışmada elde edilen bulguların oranı literatürdeki diğer çalışmaların bulgularına göre daha yüksek bulunmuştur. Ancak, bu sonuçlar, kişilerin ifadelerine dayalıdır. Gözleme dayalı bir çalışmada gerçek el yıkama oranlarının daha düşük olmasının muhtemel olduğunu da düşündürmektedir. Hastane yönetimlerinin, maliyeti en düşük, etkinliği yüksek ve uygulanması en kolay yöntem olan el hijyeni konusuna daha fazla önem vermeleri, sık sık gözlem yapmaları ve uyum davranışı göstermeyen çalışanlara daha fazla eğilmesinin önemli olduğu düşünülmektedir. Literatürde de el hijyeni davranışını iyileştirmek için çabaların çoğunca geniş tabanlı eğitim ve motivasyon programlarına odaklandığı ileri sürülmektedir (Lankford vd. 2003:217). Lankford ve diğerlerinin (2003:220) çalışmasında, el hijyeni davranışına uyumun çalışma ortamındaki rol modelden ve meslektaşlardan etkilendiği ileri sürülmektedir. Yazarlar, sağlık çalışanlarının, kendi sağlıkları için risk oluşturduğunu algllamaları halinde el hijyen uyumunun iyileştirilebileceğini öne sürmektedirler. Diğer bazı çalışmalarda da (Wendt vd. 2004:204) hastayla ya da hastanın malzemeleriyle temastan sonra el hijyenini sağlamaya yönelik solüsyon kullanım oranı oldukça yüksek bulunmuştur. Jamal ve arkadaşları (2012:173) Avustralya'da bir çocuk hastanesinde kalite iyileştirme yaklaşımıyla 2006 yılında \%23 olan el hijyeni uyumunun 2011 yılında o87'ye çıktığını bildirmişlerdir. Muto ve diğerlerinin (2000:274) gözleme dayalı çalışmasında el yıkama oranının temizlikçilerde 이, hekimlerde $\% 83$ ve hemşirelerde $\% 60$ bulunmuştur.

Balcı ve diğerlerinin (2005:161) çalışmasında iş bitiminde, yemekten önce, tuvaletten çıkınca ve eline bir şey bulaştığında el yıkama oranı \%90'ların üzerindeyken, iş bitiminde eve gitmeden önce el yıkama oranı yaklaşık 80 olarak belirtilmiştir. Terzi ve diğerlerinin çalışmasında (2009:9), temizlik çalışanlarının \%90.7'si her iş bitiminde, 63.4'ü kirli yüzeylerle temastan sonra ellerini yıkadıklarını belirtmiştir. Bu bulgular araştırma bulgularına benzer 
Tekingündüz, S., Kurt, A.Ö. ve Ayhan Temirci, H. Life Sciences (NWSALS), 4B0006, 2015; 10(4): 15-28

olarak el yıkama alışkanlıkları ile cinsiyet ve öğrenim durumu arasında fark bulunmadığı görülmektedir. Arda ve diğerlerin (2005:184) çalışmasında el temizliğine uyumu sırasıyla; anesteziyoloji ve reanimasyon yoğun bakım ünitesinde (YBÜ) (\%9.0), kalp ve damar cerrahisi YBÜ (\%4.8), nöroloji YBÜ (\%3.4) ve iç hastalıkları YBÜ (ㅇ.0) olarak belirtilmiştir.

Bulaşıcı hastalıklardan korunmanın en etkili yollarından biri kişilerin bağışıklanmasıdır (Türkistanlı, 2000:29). Yapılan bu araştırmada, çalışanların o33.7'sinin sadece Hepatit B aşısı, \%6.3'ünün sadece tetanoz, 46.7'sinin her iki aşıyı yaptırdığı, ancak o13.3'ünün bu aşıları hiç yaptırmadığı saptanmıştır. Sundukları hizmetler yönünden riskli grubu oluşturan temizlik çalışanlarının oldukça önemli olan koruyucu aşıları yaptırma oranları düşük çıkmıştır. Balcı ve diğerlerinin (2005:161) çalışmasında, Hepatit B $\square$ ye karşı aşılı olanların oranı 23.1, tetanoz aşısı yaptırma oranı da o41.5 bulunmuştur. Terzi ve diğerlerinin çalışmasında (2009:9) çalışanların, \%61'inin Hepatit B aşısını yaptırdığı; Deveci ve diğerlerinin (2010:126) çalışmasında da o17'sinin Hepatit B, o1.8'sınin Hepatit B ve Tetanoz aşısı; Ersoy ve diğerlerinin (2014) çalışmasında \%64.5'inin hepatit B, 24'ünün tetanoz aşısı yaptırdığı bildirilmiştir. Kişioğlu ve diğerlerinin (2002:394) çalışmasında, hastanedeki meslek mensupları arasında Hepatit B aşısı yaptırma oranı temizlik çalışanları arasında en düşük (\%4.1) olarak ifade edilmiştir. Janzen ve diğerlerinin (1978:263) çalışmasında da hastanede farklı meslek mensupları arasında HBsAg ve AntiHBs pozitifliğinin en yüksek olduğu grup temizlik çalışanları bulunmuştur. Araştırmada temizlik çalışanlarına yapılan aşı oranları ve literatür sonuçlarına göre temizlik çalışanları bulaşıcı hastalıklara karşı yeterince korunmamaktadır.

Yapılan bu çalışmada, temizlik çalışanlarının neredeyse yarısı (\%48.1'i) kendisinden hastalara enfeksiyon etkeni bulaşabileceğini, o52.6'sı hastadan hastaya enfeksiyon etkeni bulaştırabileceğini düşünmektedir. Ersoy ve diğerlerinin (2014) çalışmasında, çalışanların \%51.9'u kendisinin hastadan hastaya enfeksiyon etkeni bulaştırabileceğini, o41.5'i kendisinden hastalara enfeksiyon etkeni bulaşabileceğini bildirmiştir.

Araştırma bulguları ve literatürde yer alan diğer çalışma sonuçları birlikte değerlendirildiğinde temizlik çalışanlarının sağlıklarını korumakla yükümlü olan yönetimlerin/işverenlerin işçilerin eğitim alma ve aşılama oranlarına göre değerlendirildiğinde görevlerini yeterince yerine getirmedikleri ve çalışanların sağlığının risk altında olduğu düşünülmektedir.

\section{6. ÖNERILLER (RECOMMENDATIONS)}

Çalışanların dörtte birinin hijyen ve bulaşıcı hastalıklar eğitimi almaması, kişisel koruyucu kullanımının tam olmaması, iğne batması sonrasında doğru tutuma sahip olmaması, el yıkama konusunda doğru davranış göstermemesi ve aşılarının tam yapılmaması hem kendileri hem de hizmet sundukları kişiler açısından bulaşıcı hastalık riskini artırabilir. Hijyen ve bulaşıcı hastalıklar, kişisel koruyucuların kullanımı konusunda, çalışanlara konunun önemini vurgulayan etkili eğitim programlarının hazırlanması ve verilmesinin, bu alanda kullanılabilecek kılavuzların hazırlanmasının, başta tıbbi atıklar olmak üzere diğer atıkların taşınmasıyla ilgili gözlemlerin sık sık yapılmasının önemli olacağı düşünülmektedir. Hepatit $B$ ve Tetanoza karşı aşılama oranlarının yükseltilmesi sağlanmalıdır. 
Tekingündüz, S., Kurt, A.Ö. ve Ayhan Temirci, H. Life Sciences (NWSALS), 4B0006, 2015; 10(4): 15-28

\section{KAYNAKLAR (REFERENCES)}

- Allegranzi, B., Storr, J., Dziekan, G., Leotsakos, A., Donaldson, L., and Pittet, D., (2007). The first global patient safety challenge "clean care is safer care": From launch to current progress and achievements. Journal of Hospital Infection, 65 (S2), 115-123.

- Altıok, M., Kuyurtar, F., Karaçorlu, S., Ersöz, G. ve Erdoğan, S., (2009). Sağlık Çalışanlarının Delici-Kesici Aletlerle Yaralanma Deneyimleri ve Yaralanmaya Yönelik Alınan Önlemler, Maltepe Üniversitesi Hemşirelik Bilim ve Sanatı Dergisi 2(3): $70-79$.

- Arda, B., Şenol, Ş., Taşbakan, M.I., Yamazhan, T., Sipahi, O.R., Aksu, G. ve Ulusoy, S., (2005). Ege Üniversitesi Tıp Fakültesi Yoğun Bakım Ünitelerinde El Temizliği Kurallarına Uyumun Değerlendirilmesi, Yoğun Bakım Dergisi, 5:182-186.

- Balcı, E., Horoz, D., Gün, İ. ve Öztürk, y., (2005). Temizlik işinde çalışan kişilerin temizlik ve sağlık davranışlarının değerlendirilmesi. Erciyes Tıp Dergisi, 27(4):158-66.

- Beltrami, E.M., MCArthur, M.A., MCGeer, A., Armstrong-Evans, M., Lyons, D., Chamberland, M.E., and Cardo, D.M., (2000). The nature and frequency of blood contacts among home healthcare workers. Infection Control and Hospital Epidemiology, 21:765-70.

- Bilici, S., Irmak, H. ve Buzgan, T., (2008). Sağlık personeline yönelik el yıkama ve el dezenfeksiyonu rehberi. Sağlık Bakanlığı Yayın No: 726 .

- Demir, N.A., Kölgelier, S., Küçük, A., Özçimen, S., Sönmez, B., Demir, L.S. ve İnkaya, A.Ç., (2013).Sağlık Çalışanlarının El Hijyeni Hakkındaki Bilgi Düzeyi Ve El Hijyenine Uyumu, Nobel Medicus, 9(3):104-109.

- Deveci, S.E., Açık, Y., Ercan, E. ve Oğuzöncül, F., (2010). Bir Üniversite Hastanesinde Temizlik Çalışanlarının Temizlik ve Hijyen Konusundaki Davranışlarının Değerlendirilmesi, Fırat Üniversitesi Sağlık Bilimleri Tıp Dergisi, 24 (2):123-127.

- Erasmus, V., Daha, T.J., Brug, H., Richardus, J.H., Behrendt, M.D., Vos, M.C., and Beeck, F.V., (2010). Systematic review of studies on compliance with hand hygiene guidelines in hospital care. Infection Control and Hospital Epidemiology, 31:283-294.

- Ergönül, Ö., Baykan, N., Erbay, A., Taşdelen, N., Demiroğlu, Z., ve Dokuzoğuz, B., (1999). Ankara Numune Eğitim ve Araştırma Hastanesi sağlık çalışanlarının enfeksiyon riskleri hakkında bilgi, tutum ve davranışlarının değerlendirilmesi. Sağlık Çalışanlarının Sağlığı I.Ulusal Kongresi, Ankara, Kongre Kitabı.

- Ersoy, S., Çetinkaya, F. ve Alp, E., (2014). Hastane Temizlik Çalışanlarının Hastane Enfeksiyonları ve Korunma İle İlgili Bilgi, Tutum Ve Davranışları, Sağlık Bilimleri Dergisi (Journal of Health Sciences), $23(1)$.

- Feather, A., Stone, S.P., Wessier, A., Boursicot, K.A., and Pratt, C., (2000). 'Now please wash your hands': the handwashing behavior of final MBBS candidates. Journal of Hospital Infection, 45:62-64.

- Flores, A. and Pevalin, D.J., (2006). Health care workers compliance with glove use and the effect of glove use on hand hygiene compliance, Br J Infect Control, 7(6):15-9. 
Tekingündüz, S., Kurt, A.Ö. ve Ayhan Temirci, H. Life Sciences (NWSALS), 4B0006, 2015; 10(4): 15-28

- Jamal, A., O'Grady, G., Harnett, E., Dalton, D., and Andresen, D., (2012). Improving hand hygiene in a paediatric hospital: a multimodal quality improvement approach. BMJ Qual Saf. $21(2)$ : $171-6,2012$.

- Janzen, J., Tripatzis, I., Wagner, U., Schlieter, M., MüllerDethard, E., and Volters, E., (1978). Epidemiology of Hepatitis B Surface Antigen(HBsAg) And Antibody To HBsAg İn Hospital Personnel. Journal Infections Disease, 137:261-265.

- Kişioğlu, A.N., Öztürk, M., Uskun, M. ve Kırbıyık, S., (2002). Bir Üniversite Hastanesi sağlık personelinde delici kesici yaralanma epidemiyolojisi ve korunmaya yönelik tutum ve davranışları. T Klin J Med Sci, 22:390-396.

- Korkmaz, M., (2008). Sağlık Çalışanlarında Delici Kesici Alet Yaralanmaları, Fırat Sağlık Hizmetleri Dergisi, 3(9):17-37.

- Kürtünlü, Ş., (2013). Ameliyathane Çalışanlarında Delici-Kesici Aletle Yaralanma Durumu. Haliç Üniversitesi Sağlık Bilimleri Enstitüsü, Yüksek Lisans Tezi, İstanbul.

- Lankford, M.G., Zembower, T.R., Tricks, W.E., Hacek, D.M., Noskin, G.A., and Peterson, L.R., (2003). Influence of role models and hospital design on hand hygiene of health care workers. Emerging Infectious Diseases. 9(2):217-223.

- Merih, Y.D., Kocabey, M.Y., Çırpı, F., Bolca, Z. ve Celayir, A.C., (2009). Bir Devlet Hastanesinde Ü̧̧ Yıl İçerisinde Görülen Kesici-Delici Alet Yaralanmalarının Epidemiyolojisi Ve Korunmaya Yönelik Önlemler, Zeynep Kamil Tıp Bülteni, 40(1):11-15, 2009.

- Muto, C.A., Sistrom, M.G., and Farr, B.M., (2000). Hand hygiene rates unaffected by installation of dispensers of a rapidly acting hand antiseptic, American Journal of Infection control, $28(3): 273-276$.

- NIOHS., (2000). Preventing Needlestick Injuries in Health Care Settings, U.S. Department of Health and Human Services, Public Health Service Centers for Disease Control and Prevention National Institute for Occupational Safety and Health, DHHS (NIOSH) Publication No:108, ABD.

- Omaç, M., Eğri, M. ve Karaoğlu, L., (2010). Malatya Merkez Hastanelerinde Çalışmakta Olan Hemşirelerde Mesleki KesiciDelici Alet Yaralanma ve Hepatit B Bağışıklanma Durumları. İnönü Üniversitesi Tıp Fakültesi Dergisi 17(1):19-25.

- Özvarış, Ş.B., (1999). Sağlık Çalışanlarının Enfeksiyonlardan Korunması. Sürekli Tıp Eğitimi Dergisi, Aralık.

- Pittet, D. and Donaldson, L., (2005). Clean Care is Safer Care: The First Global Challenge of the WHO World Alliance for Patient Safety. Infection Control, 26, 891-894.

- Şen, S., Sönmezoğlu, M., Akbal, E., Uğur, E. ve Afacan, S., (2013). Bir Üniversite Hastanesinde Sağlık Personelinin El Hijyeninde Beş İndikasyona Uyumu, Klimik Dergisi, 26(1):17-20.

- SKS El Hijyeni Uygulaması. Temiz Eller Güvenlidir, Sağlık Bakanlı ğı. Erişim adresi: http://www.kalite.saglik.gov.tr/index.php?lang=tr\&page=192. Erişim Tarihi:27.05.2015.

- Terzi, Ö., Aker, S., Terzi, Ö., Sünter, A.T. ve Pekşen, Y., (2009). Hastane temizlik elemanları ve mesleki enfeksiyon riski: Bilgi ve davranışlar üzerine bir çalışma, İnönü Üniversitesi Tıp Fakültesi Dergisi, 16(1):7-12. 
- Türkistanlı, E., Şenuzun, F.E., Karaca, B.S., San, A.T., ve Aydemir, G., (2000). Ege Üniversitesi Tıp Fakültesi Araştırma ve Uygulama Hastanesinde sağlık çalışanlarının bağışıklama durumu. Ege Tıp Dergisi, 39:29-32.

- Wendt, C., Knautz, D., and Von Baum, H., (2004). Differences in hand hygiene behavior related to the contamination risk of healthcare activities in different groups of healthcare workers. Infect Control Hosp Epidemiol. 25 (3):203-236.

- WHO, (2004). World Alliance for Patient Safety Forward Programme 2005, http://www.who.int/patientsafety/en/brochure_final.pdf, Erişim Tarihi: 05.09.2015.

- Yamazhan, T., Taşbakan, M.I., Çalık, Ş., Pullukçu, H., Sipahi, O.R. ve Ulusoy, S., (2009). Hastanemizde çalışan temizlik elemanlarının hastane enfeksiyonlarından korunmaya yönelik bilgi düzeylerinin değerlendirilmesi, Turk J Med Sci, 39:77-80. 